Full Length Article

\title{
Formation of $\mathrm{H}_{2} \mathrm{O}$ on a $\mathrm{CO}_{2}$ dosed $\mathrm{Ru}\left(\begin{array}{llll}0 & 0 & 0 & 1\end{array}\right)$ surface under Extreme Ultraviolet Light and $\mathrm{H}_{2}$
}

\author{
B.K. Mund ${ }^{\mathrm{a}, *}$, J.M. Sturm ${ }^{\mathrm{a}}$, C.J. Lee ${ }^{\mathrm{a}, \mathrm{b}}$, F. Bijkerk ${ }^{\mathrm{a}}$ \\ ${ }^{\text {a } I n d u s t r i a l ~ F o c u s ~ G r o u p ~ X U V ~ O p t i c s, ~ M E S A ~+~ I n s t i t u t e ~ o f ~ N a n o t e c h n o l o g y, ~ U n i v e r s i t y ~ o f ~ T w e n t e, ~ E n s c h e d e, ~ T h e ~ N e t h e r l a n d s ~}$ \\ ${ }^{\mathrm{b}}$ Institute of Engineering, Fontys Hogescholen, Eindhoven, The Netherlands
}

\section{A R T I C L E I N F O}

\section{Keywords:}

Carbon dioxide

Water

Hydrogen

Ruthenium

Extreme Ultraviolet Light

\begin{abstract}
A B S T R A C T
In this work, we study the reaction of the dissociation products of carbon dioxide on a Ru(0 001$)$ surface under Extreme Ultraviolet (EUV) light with a partial pressure of hydrogen. Our results show that both amorphous carbon and $\mathrm{H}_{2} \mathrm{O}$ are the end products of the $\mathrm{CO}_{2}$ dissociation at the Ru surface, and these are produced only in the presence EUV and $\mathrm{H}_{2}$. Partial dissociation of $\mathrm{CO}_{2}$ on the Ru surface is an intermediate step in the overall reaction. Using Reflection Absorption Infrared spectroscopy (RAIRS) and Temperature Programmed Desorption (TPD), only water is detected as molecular reaction product. We further show that this reaction deactivates the $\mathrm{Ru}$ surface due to the formation of an amorphous carbon layer, thereby confirming the catalytic role of Ru in the total reaction.
\end{abstract}

\section{Introduction}

$\mathrm{CO}_{2}$ has been shown to dissociate when in contact with metal surfaces, such as $\mathrm{Fe}$ [1,2], $\mathrm{Ni}[1,2], \mathrm{W}[3]$, Re [4] and $\mathrm{Al}$ [5], into $\mathrm{CO}$ and $\mathrm{O}$ [6]. In the chemical industry, transition metals are widely studied as catalysts [7], due to their high efficiency to convert carbon dioxide to methane and methanol. Thus, to understand the transition metal driven catalytic conversion of $\mathrm{CO}_{2}$ to other compounds, the interaction of $\mathrm{CO}_{2}$ with metal surfaces needs to be studied [8].

Besides its relevance for catalysis, $\mathrm{Ru}$ is also employed as a protective cap for optics for Extreme Ultraviolet (EUV) light. EUV optics must operate in a moderate vacuum where there may be a complex balance between, on the one side photochemical reactions of residual hydrocarbons and water on the cap, and on the other side, cleaning by hydrogen radicals. One option to control reaction pathways is to deliberately introduce additional species into the vacuum to consume reactive species. For instance, a balance between ruthenium oxidation and reduction is achieved by controlling the partial pressure of either hydrogen or water [9].

The dissociation products of $\mathrm{CO}_{2}$ reacting with hydrogen to form hydrocarbons on the optics surfaces to prevent oxidation and consume excess reactive hydrogen is an attractive prospect in highly reactive environments, such as in the case of Extreme Ultraviolet (EUV) Lithography. However, to prevent oxidation and consume hydrogen via this pathway, a reverse water gas shift reaction needs to take place [10]. Ruthenium surfaces have previously been used as catalyzing agents for reverse water gas shift reactions, but ruthenium's interaction with $\mathrm{CO}_{2}$ has not been fully investigated $[8,11]$. Furthermore, this catalyzing behavior is shown in Density Functional Theory (DFT) calculations as well, where $\mathrm{CO}_{2}$ adsorption and dissociation is seen on a $\mathrm{Ru}$ surface, hydrogenating to form $\mathrm{CH}_{\mathrm{x}}$ species $[12,13]$.

Prior experiments [14] have shown that $\mathrm{CO}_{2}$ adsorption on a $\mathrm{Ru}$

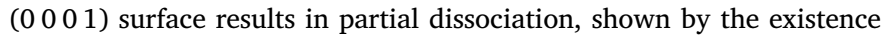
of both $\mathrm{CO}_{2}$ and $\mathrm{CO}$ species on the surface. Furthermore, this dissociation was observed to saturate with increasing $\mathrm{CO}_{2}$ coverage. Additionally, no evidence was found for oxygen desorption, indicating that the oxygen was consumed by forming additional $\mathrm{CO}$ and/or $\mathrm{H}_{2} \mathrm{O}$ via reactions with residual carbon and/or hydrogen on the crystal surface.

However, these experiments were not extended to more realistic scenarios, involving the presence of hydrogen and EUV. Thus, it is unknown if the partial dissociation of $\mathrm{CO}_{2}$ is sufficient to induce further reactions with excess hydrogen. In order to understand the preferred reaction pathways under more realistic conditions for EUV optics, the

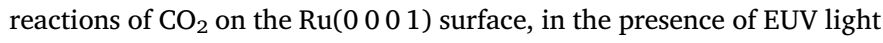
and $\mathrm{H}_{2}$ are studied in more detail in this work.

For this work, the surface was characterized, in-situ, using Reflection Absorption Infrared Spectroscopy (RAIRS) and Temperature Programmed Desorption (TPD) spectroscopy. RAIRS measurements are sensitive to study the changes in adsorbed molecular groups, their orientation, density, and surrounding environment via changes in vibrational modes.

\footnotetext{
* Corresponding author.

E-mail address: b.k.mund@utwente.nl (B.K. Mund).
} 


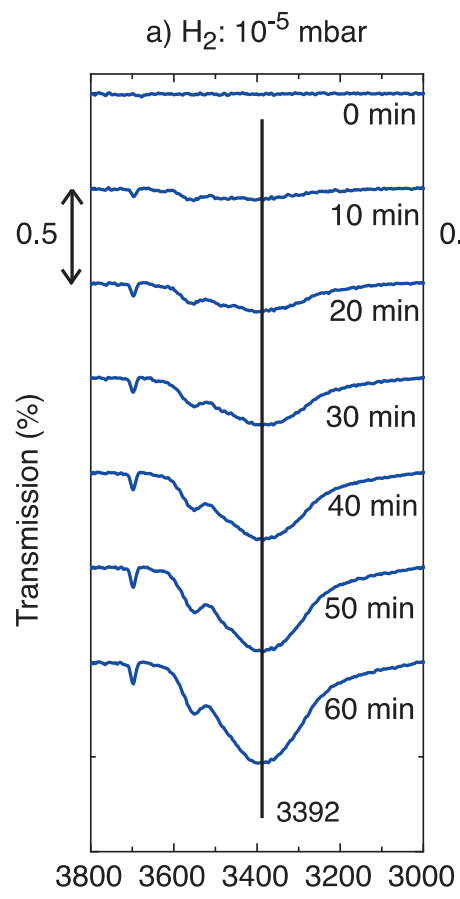

b) $\mathrm{CO}_{2}+\mathrm{H}_{2}: 10^{-5} \mathrm{mbar}$

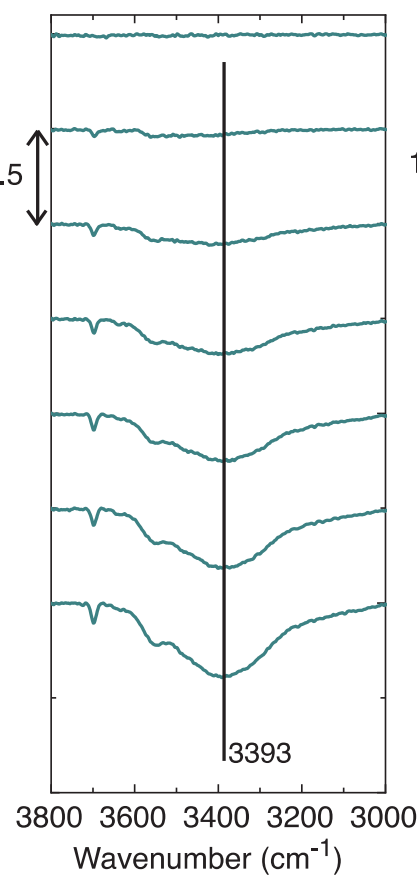

c) $\mathrm{EUV}+\mathrm{CO}_{2}+\mathrm{H}_{2}: 10^{-5} \mathrm{mbar}$

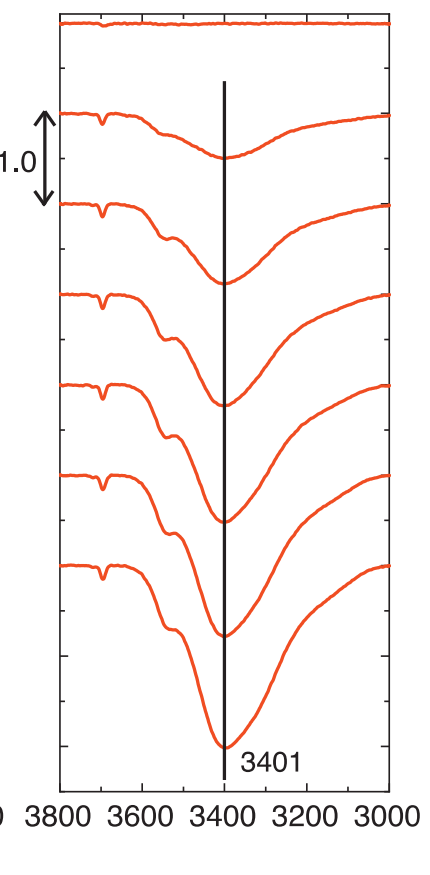

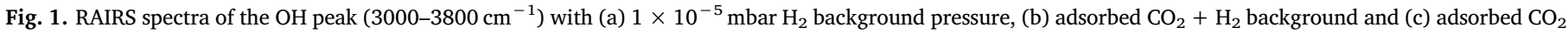
and $\mathrm{H}_{2}$ background under EUV irradiation. Spectra are shown in 10-min exposure increments from top to bottom.

\section{Experimental}

For this work, a ruthenium $\left(\begin{array}{llll}0 & 0 & 0 & 1\end{array}\right)$ single crystal, $11 \mathrm{~mm}$ in diameter and $\sim 3 \mathrm{~mm}$ in thickness, prepared by Surface Preparation Laboratories, The Netherlands, was used. The crystal was mounted on a 3-axis positioning manipulator in Ultra-High Vacuum (UHV) conditions and maintained at a base pressure of $10^{-10} \mathrm{mbar}$. A K-type thermocouple is spot welded to the side of the crystal to measure the surface temperature. A Eurotherm temperature controller was used to control the temperature of the surface.

All surface chemistry experiments were performed in the same experimental setup, sequentially without breaking vacuum. The crystal surface was treated with a cleaning process involving oxidation, annealing and argon ion sputtering. Firstly, oxidation was performed to remove carbon from the surface, by increasing the surface temperature to $1300 \mathrm{~K}$, with a partial pressure of $1 \times 10^{-7} \mathrm{mbar}$ of $\mathrm{O}_{2}$ in the chamber. Secondly, ion sputtering was conducted. Finally, the surface was annealed at $1300 \mathrm{~K}$ for $30 \mathrm{~min}$ and flashed to $1580 \mathrm{~K}$. Repeated sputtering and annealing was performed until a reference TPD spectrum from water and CO on clean Ru(0 001$)$ could be reproduced [15].

The experimental chamber is also equipped with RAIRS and TPD spectroscopy, and is attached to an EUV source [16,17]. RAIRS spectra are measured at grazing incidence using a Fourier Transform Infrared Spectrometer (Bruker vertex $70 \mathrm{~V}$ ), equipped with a liquid $\mathrm{N}_{2}$ cooled mercury-cadmium-telluride (MCT) detector. Each IR spectrum is accumulated over 256 scans with a resolution of $4 \mathrm{~cm}^{-1}$, with background and measurement scans recorded at $85 \mathrm{~K}$. To obtain TPD spectra, the surface is placed $\sim 1 \mathrm{~mm}$ away from the entrance aperture of a Hiden Analytical 3F/PIC quadrupole mass spectrometer (QMS), housed in a differential pumped system, to ensure the signal is dominated by surface desorption.

Carbon dioxide (99.998\% purity; residuals: $\mathrm{O}_{2} 2 \mathrm{ppm}, \mathrm{N}_{2} 8 \mathrm{ppm}$, hydrocarbon $3 \mathrm{ppm}, \mathrm{H}_{2} \mathrm{O} 1 \mathrm{ppm}, \mathrm{CO} 1 \mathrm{ppm}$ ) was dosed on the surface at a temperature of $85 \mathrm{~K}$. This was done using a retractable quartz dosing tube, placed $1 \mathrm{~cm}$ away from the surface. $\mathrm{CO}_{2}$ is delivered via a pinhole mounted between the gas supply and doser, to maintain an effective pressure in the $10^{-8}$ mbar range near the crystal surface. Calibration of $\mathrm{CO}_{2}$ dose was performed by comparing the amount detected via TPD against reference water TPD spectra [14,17].

The chamber is attached to a Xe plasma discharge EUV source (Philips EUV Alpha Source) with a repetition rate of $500 \mathrm{~Hz}$. The light from the source is filtered via reflection from a Mo/Si multilayer mirror (55\% reflectivity at $13.5 \mathrm{~nm}$ ) and via transmission through a Si/Mo/Zr membrane (35\% transmission at $13.5 \mathrm{~nm}$ ) [18], resulting in a peak transmission of $19 \%$ at $13.5 \mathrm{~nm}$ with a FWHM of $0.2 \mathrm{~nm}$ and an additional transmission of $9 \%$ at $21.5 \mathrm{~nm}$ with a FWHM of $3.1 \mathrm{~nm}$ $[19,20,21]$. The average intensity of the EUV beam, with a Gaussian profile (FWHM $=3 \mathrm{~mm}$ ) is $35-55 \mathrm{~mW} / \mathrm{cm}^{2}$, which corresponds to an EUV pulse fluence of $90-110 \mu \mathrm{J} / \mathrm{cm}^{2}$.

The experimental procedure begins with dosing the cleaned (unless otherwise noted) $\mathrm{Ru}(0001)$ surface with $0.2 \mathrm{ML}$ of $\mathrm{CO}_{2}$, followed by exposing the surface to EUV with a partial pressure of $\mathrm{H}_{2}$. A RAIRS background spectrum is recorded before dosing, and further spectra are recorded after dosing, and for every $5 \mathrm{~min}$ of EUV or $\mathrm{H}_{2}$ exposure. TPD measurements are performed by heating the crystal to $600 \mathrm{~K}$ from $80 \mathrm{~K}$ at a rate of $2 \mathrm{~K} / \mathrm{s}$, followed by further heating to $1580 \mathrm{~K}$ at $10 \mathrm{~K} / \mathrm{s}$.

\section{Results and discussion}

To investigate the dissociation of $\mathrm{CO}_{2}$ and its end product formation, experiments were first performed with an $\mathrm{H}_{2}$ partial pressure of $1 \times 10^{-7}$ mbar under EUV illumination. In this case, characterization techniques such as RAIRS and TPD were unable to detect the formation of $\mathrm{H}_{2} \mathrm{O}$ and simple hydrocarbons (such as methane, ethylene, formic acid, and methanol). Also, changing the $\mathrm{H}_{2}$ partial pressure to $1 \times 10^{-6}$ mbar, while keeping all the other parameters $\left(\mathrm{CO}_{2}\right.$, EUV) the same, did not result in any change in RAIRS OH signals (to detect water) or TPD mass spectra. Therefore, the partial pressure of $\mathrm{H}_{2}$ was further increased to $1 \times 10^{-5}$ mbar (keeping the parameters for EUV and $\mathrm{CO}_{2}$ the same), for which the results are detailed below. 


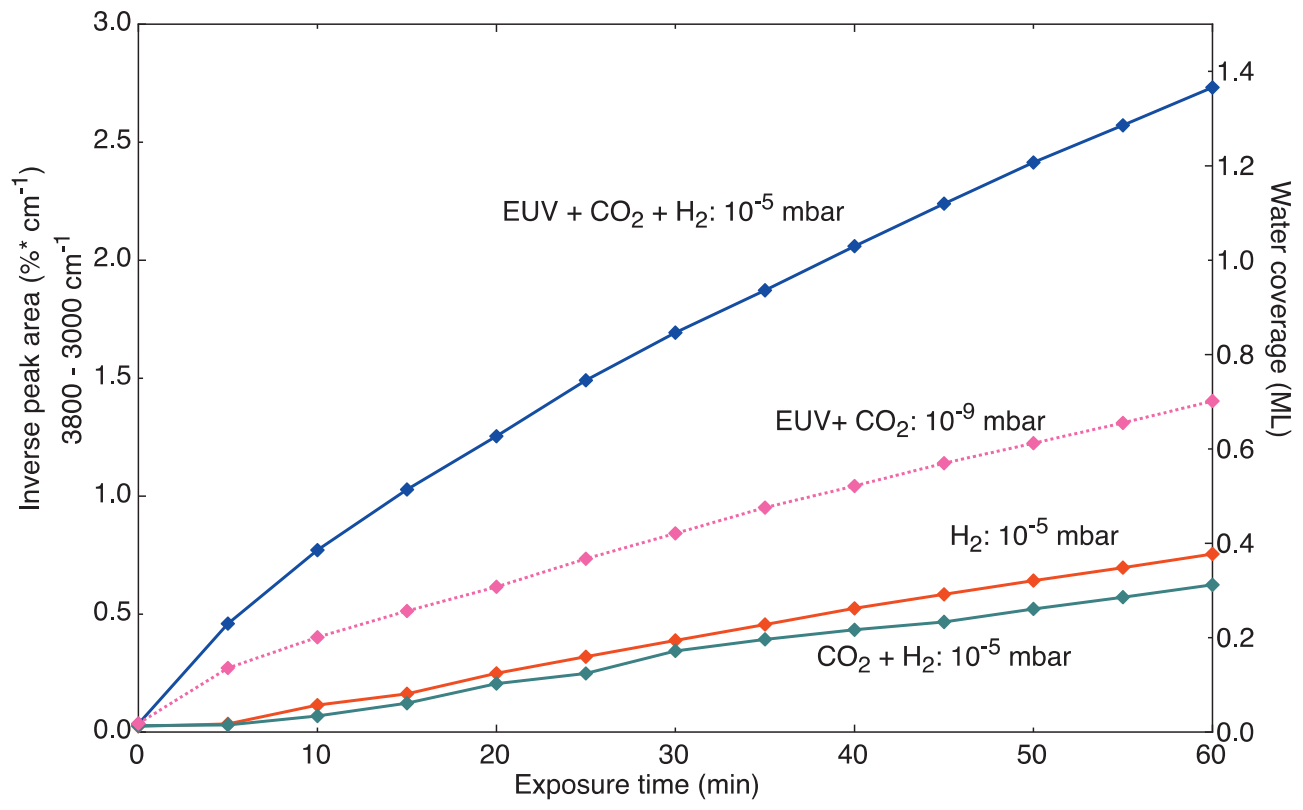

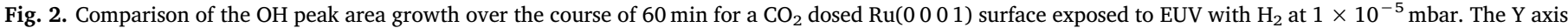
on the left shows the area under the inverse IR peak $\left(3800-3000 \mathrm{~cm}^{-1}\right)$, while the $\mathrm{Y}$ axis on the right shows the corresponding indicative water coverage.

\subsection{EUV induced surface water formation}

Fig. 1 shows the difference in RAIRS $\mathrm{OH}$ vibration peak size, which is sensitive for adsorption of molecular $\mathrm{H}_{2} \mathrm{O}$ on the surface, for different exposure conditions. As seen in Fig. 1(a), the peak intensity increases with $\mathrm{H}_{2}$ exposure time for a clean $\mathrm{Ru}(00001)$ surface, indicating increasing water deposition. This water is due to an increased residual $\mathrm{H}_{2} \mathrm{O}$ gas pressure from the $\mathrm{H}_{2}$ gas line [22]. Similarly, an increase in $\mathrm{OH}$ peak intensity is seen in Fig. 1(b) for $\mathrm{H}_{2}$ exposure of a $\mathrm{Ru}(0001)$ surface with adsorbed $\mathrm{CO}_{2}$. However, the $\mathrm{OH}$ intensity is lower than it was in the plot shown in Fig. 1(a). This is due to $\mathrm{CO}_{2}$ (or its partial dissociation products) occupying sites on the surface which prevent

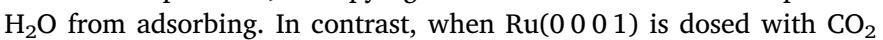
and exposed to $\mathrm{H}_{2}$ and EUV radiation (Fig. 1(c)), the $\mathrm{OH}$ peak intensity is significantly higher than for the other two conditions, with the only difference being the introduction of EUV. This indicates that more water is formed on the $\mathrm{CO}_{2}$ covered $\mathrm{Ru}(0001)$ surface when exposed to EUV in the presence of hydrogen. Fig. 2 shows the rate of $\mathrm{OH}$ peak formation.

Fig. 2 compares the growth rate of the $\mathrm{OH}$ peak for the three exposure conditions shown in Fig. 1. Water coverage is expressed in terms of both peak area and water coverage. It should be noted that RAIRS is in general not quantitative. However, based on a calibration of RAIRS versus TPD results on $\mathrm{Ru}\left(\begin{array}{llll}0 & 0 & 0 & 1\end{array}\right)$ in the same experimental set-up, an indicative water coverage can be provided based on comparison of the peak height in the transmission plots [16]. We see that water coverage increases on the surface over $60 \mathrm{~min}$ for all three cases: $0.33 \mathrm{ML}$ for $\mathrm{CO}_{2}+\mathrm{H}_{2}, 0.37 \mathrm{ML}$ for $\mathrm{H}_{2}$, and 1.36 ML for $\mathrm{EUV}+\mathrm{CO}_{2}+\mathrm{H}_{2}$. When a clean $\mathrm{Ru}\left(\begin{array}{lll}0 & 0 & 0\end{array}\right)$ ) surface is dosed with $\mathrm{CO}_{2}$ and exposed to EUV without introducing $\mathrm{H}_{2}$, the deposition of water from residual gas amounts to $0.70 \mathrm{ML}$ in $60 \mathrm{~min}$. Furthermore, water deposited in the presence of EUV without $\mathrm{CO}_{2}$ and $\mathrm{H}_{2}$ is shown to be less than $0.1 \mathrm{ML}$. The difference in final water coverage between $\mathrm{EUV}+\mathrm{CO}_{2}+\mathrm{H}_{2}$ compared to $\mathrm{CO}_{2}+\mathrm{H}_{2}$ without EUV is thus $1.03 \mathrm{ML}$. The individual contributions due to $\mathrm{EUV}+\mathrm{CO}_{2}$ and $\mathrm{CO}_{2}+\mathrm{H}_{2}$ added together would amount to $1.03 \mathrm{ML}$, which is also less compared to exposure to EUV $+\mathrm{CO}_{2}+\mathrm{H}_{2}$. The clearly higher water coverage after EUV $+\mathrm{H}_{2}$ exposure of a $\mathrm{CO}_{2}$ dosed $\mathrm{Ru}(0001)$ surface in comparison with all reference cases indicates that water is produced by an EUV-induced reaction of $\mathrm{CO}_{2}$ and $\mathrm{H}_{2}$ or its partial dissociation products.
The formation of water can be attributed to the overall reaction equation (Fischer-Tropsch type reaction):

$\mathrm{CO}_{2}+(2+n) \mathrm{H}_{2} \mathrm{EUVCH}_{2 n}+2 \mathrm{H}_{2} \mathrm{O}$

Although Eq. (1) could be a direct process, previous experiments [14] have shown that $\mathrm{CO}_{2}$ partially dissociates on $\mathrm{Ru}\left(\begin{array}{lll}0 & 0 & 0\end{array}\right)$ without EUV exposure, therefore a second reaction path is also possible:

$\mathrm{CO}_{2} \rightarrow \mathrm{CO}+\mathrm{O}$ (adsorbed)

$\mathrm{CO}+\mathrm{O}$ (adsorbed) $+(2+n) \mathrm{H}_{2} \mathrm{EUVCH}_{2 n}+2 \mathrm{H}_{2} \mathrm{O}$

In what follows, we show that the formation of water, under reaction conditions investigated here, proceeds only via the second path.

Eqs. (1) and (3) show that molecular hydrogen cracks into atomic hydrogen in the presence of EUV [20], Both Eqs. (1) and (3) lead to the formation of hydrocarbons $\left(\mathrm{CH}_{\mathrm{x}}\right)$ and water as products. Since we do not see the formation of volatile hydrocarbons, the value of $n$ can be 0 , indicating the formation of amorphous carbon. Also, Eq. (2) can only occur on the surface of $\mathrm{Ru}\left(\begin{array}{lll}0 & 0 & 0\end{array}\right)$ [14], this means Eq. (3) is limited by the formation of $\mathrm{CO}$.

Fig. 3 shows the RAIRS spectra of a clean $\mathrm{CO}_{2}$ dosed $\mathrm{Ru}\left(\begin{array}{lll}0 & 0 & 0\end{array}\right)$ surface before any EUV and $\mathrm{H}_{2}$ experiments have taken place. Three distinct peaks are visible, one for $\mathrm{CO}_{2}$ at $2343 \mathrm{~cm}^{-1}$ corresponding to a $\left(\nu_{3}\right) \mathrm{C}=\mathrm{O}$ stretch [23], and two for $\mathrm{CO}$ at $2213 \mathrm{~cm}^{-1}$ and $1993 \mathrm{~cm}^{-1}$ corresponding to a $\mathrm{C}=\mathrm{O}$ bend and a $\mathrm{C}=\mathrm{O}$ stretch, respectively [24]. This result shows that for the $\mathrm{CO}_{2}$ dose used in this study, most of the dosed $\mathrm{CO}_{2}$ partially dissociates to $\mathrm{CO}$ before the RAIRS spectrum is acquired.

In Fig. 4 , the $\mathrm{C}=\mathrm{O}$ stretch for $\mathrm{CO}$ is visible when $\mathrm{CO}_{2}$ is first dosed on the surface, followed by exposure to EUV. Fig. 4(a) shows spectra for a reference experiment where a $\mathrm{CO}_{2}$ dosed $\mathrm{Ru}\left(\begin{array}{lll}0 & 0 & 0\end{array}\right)$ surface was exposed to EUV without presence of $\mathrm{H}_{2}$ (other than residual gas) during exposure. In this case the $\mathrm{CO}$ peak intensity increases over $30 \mathrm{~min}$ of exposure, most likely due to adsorption of $\mathrm{CO}$ from residual gas. $\mathrm{As}_{2}$ is introduced at pressures of $1 \times 10^{-7} \mathrm{mbar}$ and $1 \times 10^{-5} \mathrm{mbar}$ in Fig. 4(b) and (c), respectively, we see that the CO peak intensity actually decreases over time, indicating dissociation of $\mathrm{CO}$ by a reaction that only proceeds under EUV irradiation in $\mathrm{H}_{2}$ background. Additionally, we observe that there is no corresponding increase in the $\mathrm{OH}$ peak from adsorbed water at $1 \times 10^{-7} \mathrm{mbar}_{2}$, while adsorbed water 


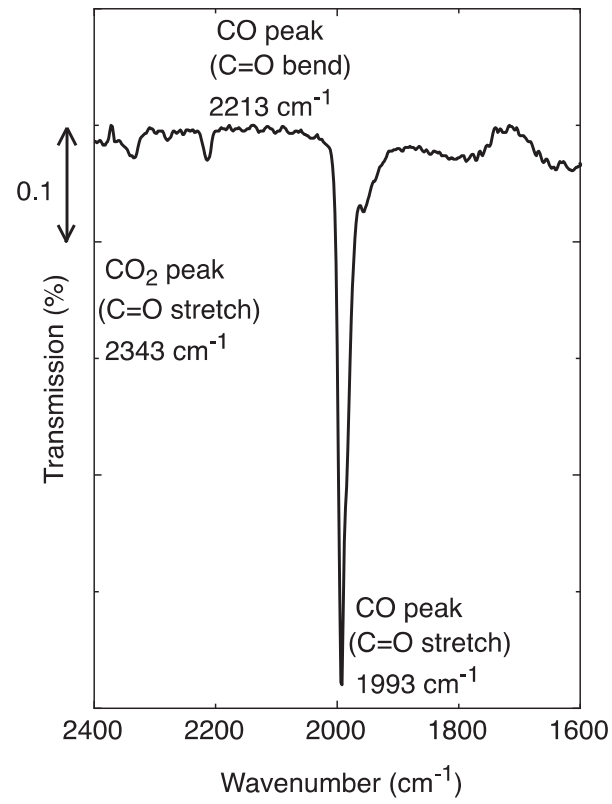

Fig. 3. RAIRS spectra of a $\mathrm{CO}_{2}$ dosed $\mathrm{Ru}\left(\begin{array}{llll}0 & 0 & 0 & 1\end{array}\right)$ surface before exposure to EUV and $\mathrm{H}_{2}$. The surface has been dosed with $0.2 \mathrm{ML}$ of $\mathrm{CO}_{2}$, and maintained at $85 \mathrm{~K}$.

is produced at an $\mathrm{H}_{2}$ pressure of $1 \times 10^{-5}$ mbar (see Figs. 1 and 2).

While the sharp CO peak decreases under exposure to EUV and $\mathrm{H}_{2}$, the formation and increase of a broad peak around $1983 \mathrm{~cm}^{-1}$ is observed, which might correspond to the vibrational frequencies of several simple hydrocarbons (methane, ethylene and propadiene) [23].
However, since no other desorbing species than $\mathrm{H}_{2} \mathrm{O}, \mathrm{H}_{2}, \mathrm{CO}_{2}$ and $\mathrm{CO}$ are detected by TPD, this indicates that amorphous $\mathrm{C}$ and/or $\mathrm{C}_{\mathrm{x}} \mathrm{H}_{\mathrm{y}}$ species stay bound to the surface. Furthermore, the broad peak may be caused by $\mathrm{CO}$ molecules that have a different binding strength to the surface due to a change in coverage and the presence of co-adsorbed molecules or $\mathrm{C}_{\mathrm{x}} \mathrm{H}_{\mathrm{y}}$ species [25].

This comparison of EUV exposure at different $\mathrm{H}_{2}$ pressures thus shows that the dissociation of $\mathrm{CO}$ is not a pure photochemical reaction. Only in the presence of $\mathrm{H}_{2}$ and/or $\mathrm{H}$ radicals produced by EUV radiation, EUV exposure leads to dissociation of $\mathrm{CO}$ into amorphous (hydro) carbon and oxygen adsorbed on the Ru surface. At an $\mathrm{H}_{2}$ pressure of $1 \times 10^{-7}$ mbar, no significant formation of $\mathrm{H}_{2} \mathrm{O}$ by reactions of adsorbed $\mathrm{O}$ with $\mathrm{H}$ radicals is observed. Only at a pressure of $1 \times 10^{-5} \mathrm{mbar}_{2}$, water is produced by (EUV induced) reactions of $\mathrm{H}_{2}$ and adsorbed oxygen originating from (partial) dissociation of $\mathrm{CO}_{2}$.

More evidence for the formation of water due to the presence of $\mathrm{CO}_{2}$, EUV and $\mathrm{H}_{2}$ is presented in Fig. 5. Under EUV, $\mathrm{CO}_{2}$ and $\mathrm{H}_{2}$, the amount of water on the surface is measured to increase by a factor of 3.7 and 4.1 when compared to water coverage of a surface only exposed to $\mathrm{H}_{2}$ and $\mathrm{CO}_{2}+\mathrm{H}_{2}$ respectively, while only EUV and $\mathrm{CO}_{2}$ produce $0.70 \mathrm{ML}$ of water, a factor 0.5 as compared to the surface exposed to EUV, $\mathrm{CO}_{2}$ and $\mathrm{H}_{2}$.

Furthermore, TPD spectra showed us that the other products desorbing from the surface were $\mathrm{CO}_{2}, \mathrm{CO}$ and $\mathrm{H}_{2}$. Simple hydrocarbons, such as methane (mass 16), ethylene (mass 28), methanol (mass 31 ), ethanol and formic acid (both mass 46), and formate (desorption of $\mathrm{CO}_{2}$ and $\mathrm{H}_{2}$ at the same temperature) [26], were not detected. Therefore, it is highly likely that non-volatile reaction products, such as (hydrogenated) amorphous carbon are formed on the surface, although it cannot be fully excluded that small molecules undergo EUV induced desorption. (a): $\mathrm{EUV}+\mathrm{CO}_{2}, \mathrm{no} \mathrm{H}_{2}$

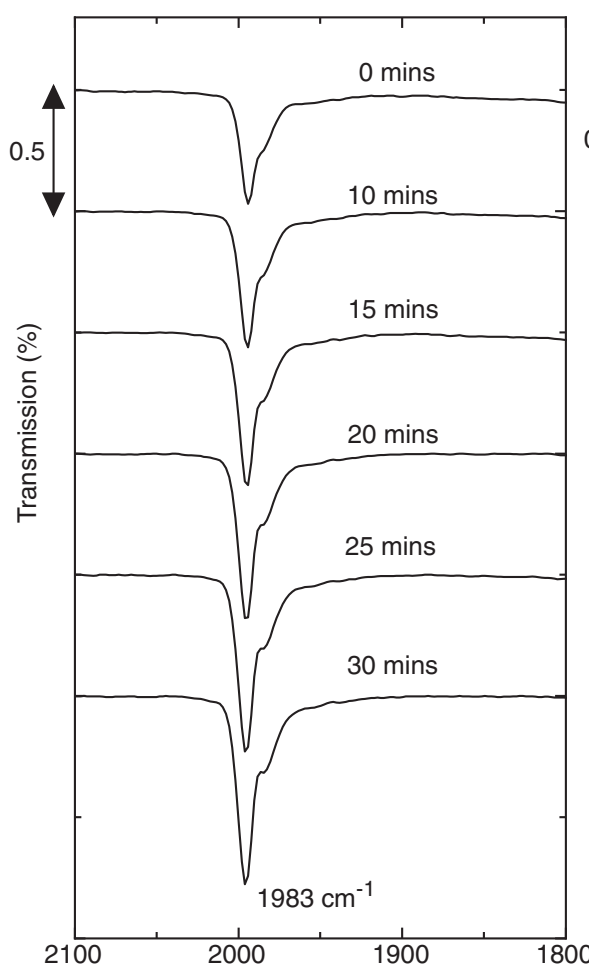

(b): $\mathrm{EUV}+\mathrm{CO}_{2}+\mathrm{H}_{2}$ $10^{-7} \mathrm{mbar}$

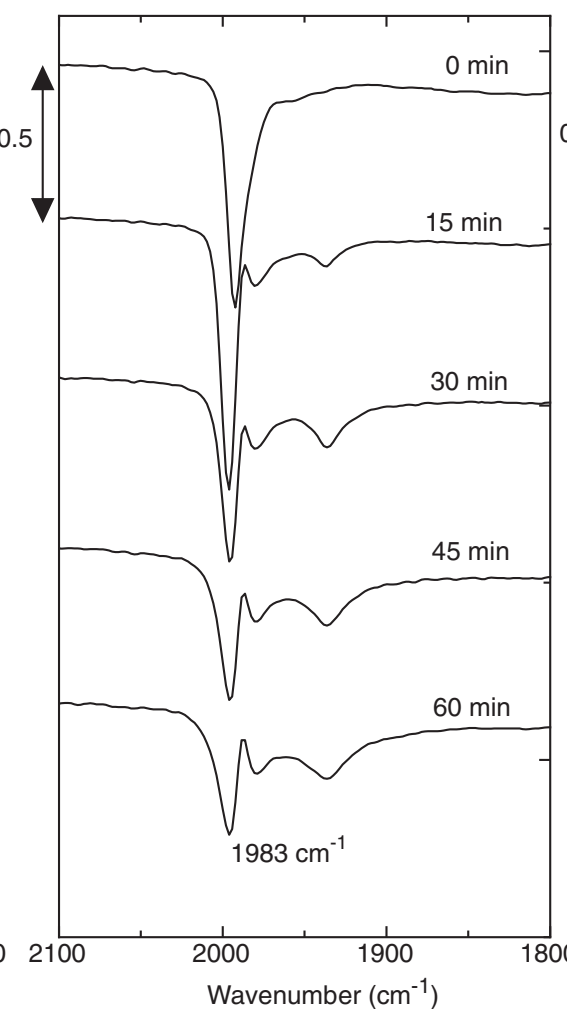

(c): $\mathrm{EUV}+\mathrm{CO}_{2}+\mathrm{H}_{2}$ $10^{-5} \mathrm{mbar}$

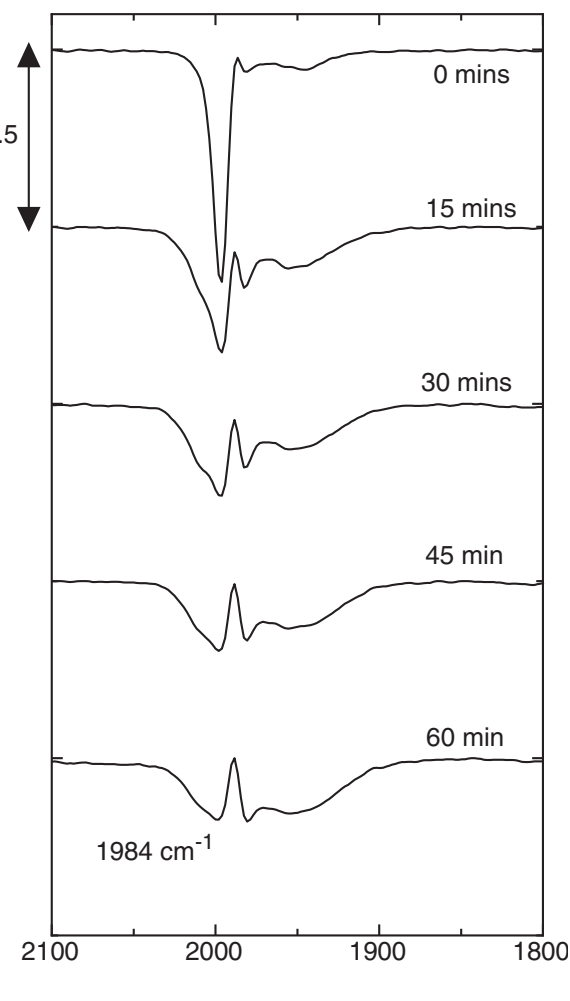

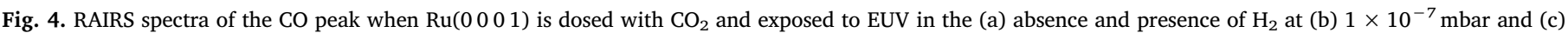
$1 \times 10^{-5}$ mbar. The EUV exposure time is indicated on each plot. 


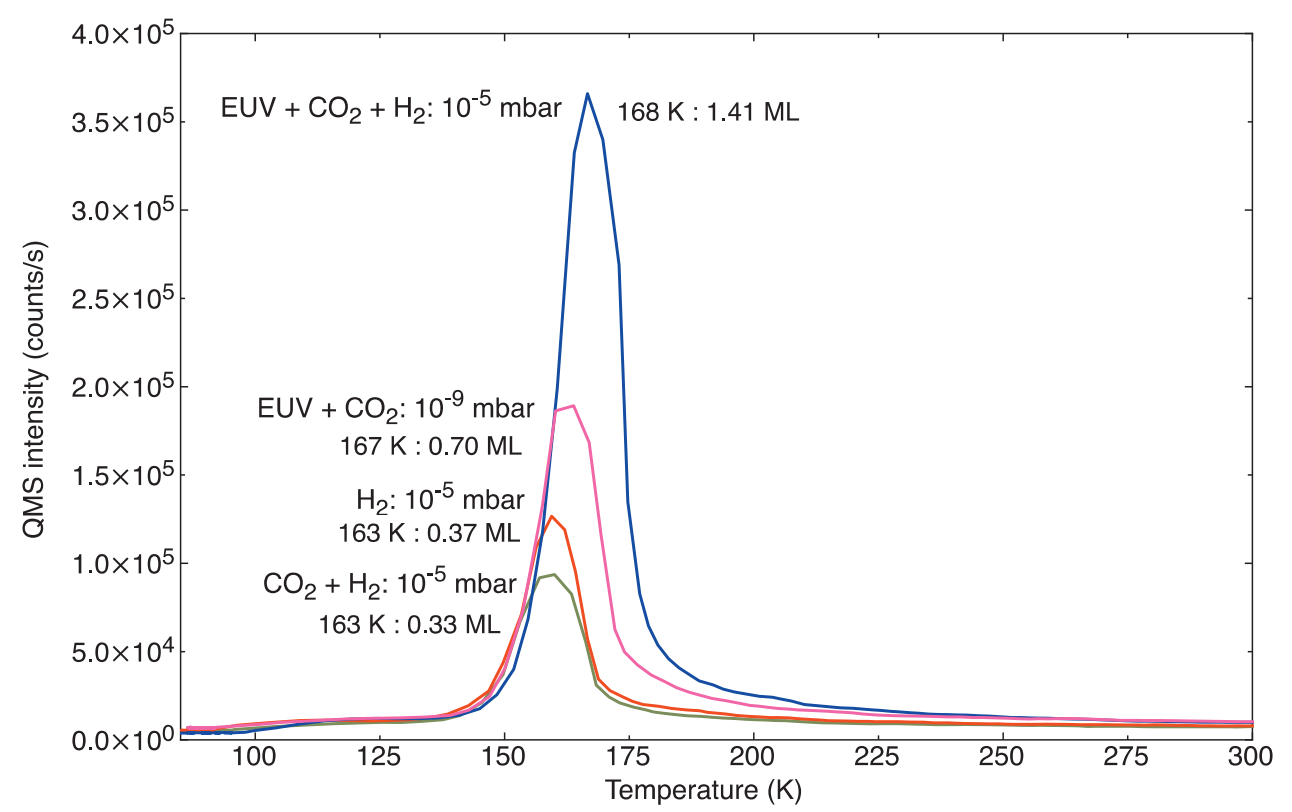

Fig. 5. TPD spectra of $\mathrm{H}_{2} \mathrm{O}$ (mass 18) for different exposure conditions after $60 \mathrm{~min}: \mathrm{H}_{2}$, $\mathrm{CO}_{2}+\mathrm{H}_{2}, \mathrm{EUV}+\mathrm{CO}_{2}+\mathrm{H}_{2}$ at $1 \times 10^{-5}$ mbar and $\mathrm{EUV}+\mathrm{CO}_{2}$ at $10^{-9}$ mbar. The plot indicates the peak desorption temperature and water coverage on the surface after $60 \mathrm{~min}$ in monolayers (ML), as compared to TPD peak areas on clean $\operatorname{Ru}\left(\begin{array}{l}0 \\ 0\end{array} 0\right.$ 1) $[14,16]$. The spectra have been smoothed over 4 values over temperature.

\subsection{Coverage of $R u(0001)$ surface with amorphous carbon/hydrocarbons}

If the formation of water requires partial dissociation of $\mathrm{CO}_{2}$ to $\mathrm{CO}$ as a first step, then water formation could be limited by the availability of catalytic sites on the Ru surface. The formation of amorphous carbon implies that Ru sites are gradually covered with amorphous carbon/ hydrocarbons. In order to find out whether the EUV-induced reaction of $\mathrm{CO}_{2}$ and $\mathrm{H}_{2}$ indeed leads to amorphous carbon formation on Ru surface sites, and to confirm that the Ru surface has a catalytic role in the $\mathrm{CO}_{2}$ dissociation reaction, the de-activation of the $\mathrm{CO}_{2}$ dissociation reaction was studied using multiple reaction cycles.

An, initially clean, surface was exposed to 5 consecutive cycles (or iterations) consisting of $\mathrm{CO}_{2}$ dosing, followed by $60 \mathrm{~min}$ exposure to EUV and $\mathrm{H}_{2}$ without sputtering or high temperature annealing the surface in between the cycles. After each cycle, the surface temperature was only increased to $600 \mathrm{~K}$ for a TPD spectrum. This ensures that any amorphous carbon formed on the surface stays adsorbed on the surface. For each cycle, the same amount of $\mathrm{CO}_{2}(0.2 \mathrm{ML})$ was dosed on the surface at $85 \mathrm{~K}$.

Fig. 6 shows that the intensity of the $\mathrm{OH}$ peak reduces with repeated exposures of EUV and $\mathrm{H}_{2}$ on a $\mathrm{CO}_{2}$ dosed Ru surface, with the intensity for iteration $\mathrm{V}$ being reduced by a factor of 4 compared to the intensity for iteration I. This indicates that water generation on the surface is reduced with each cycle.

Fig. 7 shows the water TPD spectra corresponding to the RAIRS experiment from Fig. 6, with an indication of the water coverage reached after $60 \mathrm{~min}$ of EUV exposure time, based on reference experiments of water on clean $\mathrm{Ru}(0001)[16,17]$. The intensity of the $\mathrm{OH}$ peak decreases with each iteration EUV and $\mathrm{H}_{2}$ exposure. These results confirm that the water produced by the EUV-induced reaction of $\mathrm{CO}_{2}$ and $\mathrm{H}_{2}$ decreases for an increasing number of iterations. The final water coverage in the fifth reaction cycle is reduced by a factor of 2 compared to the first reaction cycle. We attribute the reduction to a lower availability of Ru surface sites as they are covered with amorphous carbon.

Water on the surface is shown to come from two sources: the $\mathrm{H}_{2}$ line or exchange reactions on walls [15] and hydrogen reacting with $\mathrm{CO}$. As mentioned before, after $60 \mathrm{~min}, 0.33 \mathrm{ML}$ was attributed to the water deposited on the surface from the $\mathrm{H}_{2}$ line for a reference measurement of $\mathrm{CO}_{2}+\mathrm{H}_{2}$ without EUV, while $\mathrm{CO}_{2}$ reacting with EUV produces $0.70 \mathrm{ML}$. We speculate that the production of water in the latter case is due to reactions of $\mathrm{CO}_{2}$ with residual hydrogen on surfaces in the

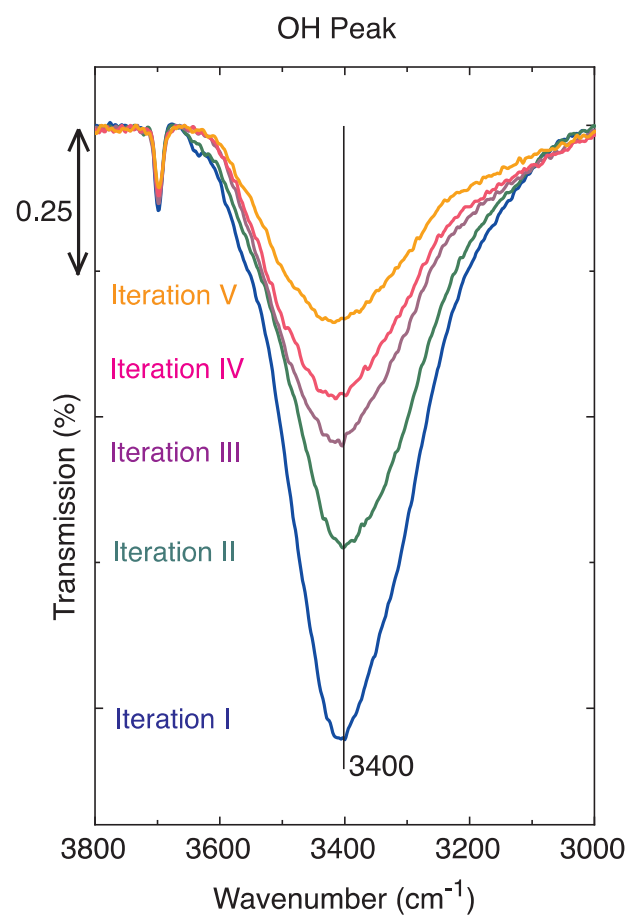

Fig. 6. RAIRS spectra of $\mathrm{OH}$ peak for cycles of $\mathrm{CO}_{2}$ dosed $\mathrm{Ru}(0001)$ after exposure to EUV and $\mathrm{H}_{2}$ for $60 \mathrm{~min}$. After each exposure the sample is heated to $600 \mathrm{~K}$, after which new $\mathrm{CO}_{2}$ is adsorbed at $85 \mathrm{~K}$. A new background is taken for each iteration, just before $\mathrm{CO}_{2}$ dosing.

system exposed to EUV. Assuming that water adsorbs on the surface at the same rate for a clean and carbon contaminated surface, we can say that about $1.36-(0.70+0.33)=0.33 \mathrm{ML}$ of the water adsorbed at the end of the reaction cycle is from $\mathrm{H}_{2}$ reacting with $\mathrm{CO}$ on the $\mathrm{Ru}$ crystal in the presence of EUV. It should be noted that such a quantitative comparison is not straightforward in view the long reaction times that inevitably lead to adsorption of residual water. However, this quantification of the amount of water formed from reactions on the $\mathrm{Ru}$ $\left(\begin{array}{lll}0 & 0 & 1\end{array}\right)$ surface seems reasonably in line with the initial dose of $\sim 0.2 \mathrm{ML} \mathrm{CO}_{2}$ and the stoichiometry from reaction (1)-(3), when taking into account that some $\mathrm{CO}$ was left on the surface at the end of the reaction cycle. 


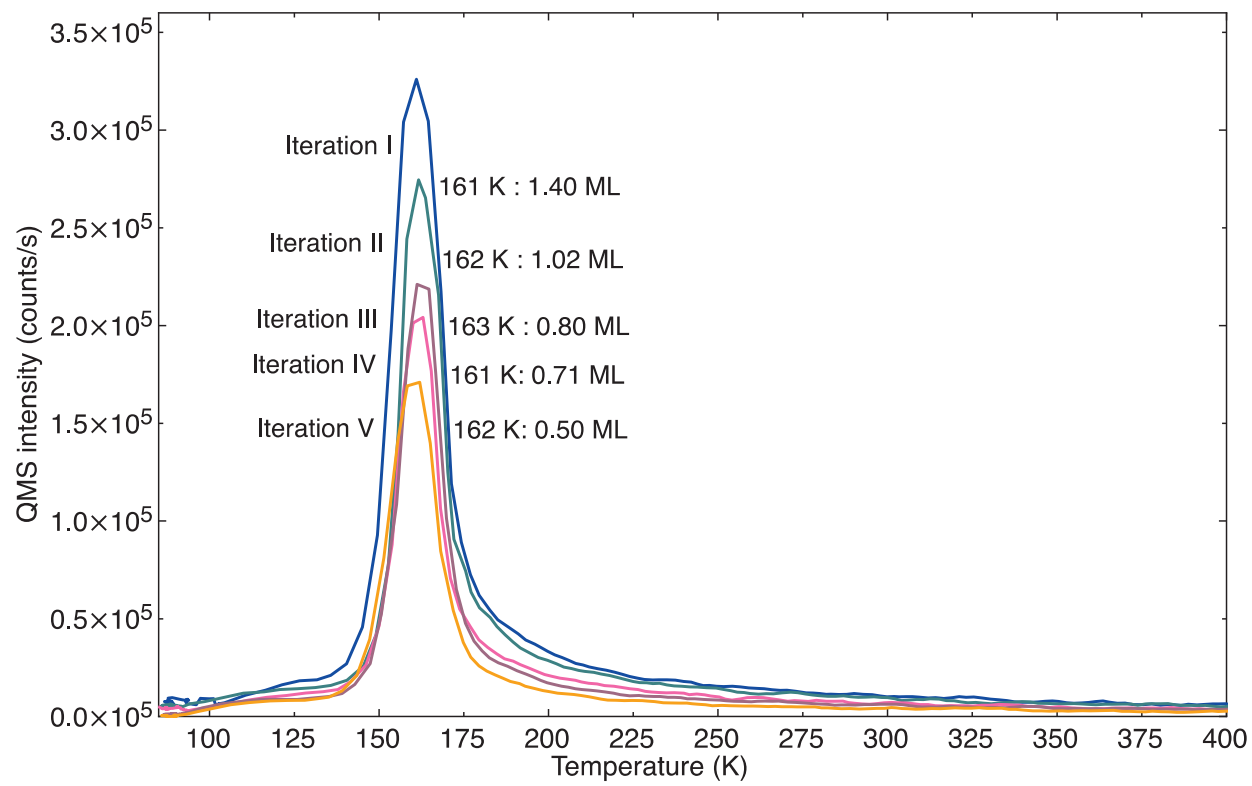

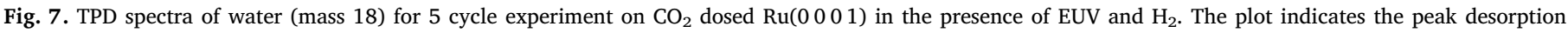
temperature and water coverage on the surface after 60 min exposure in monolayers (ML). The spectra has been smoothed over 4 values.

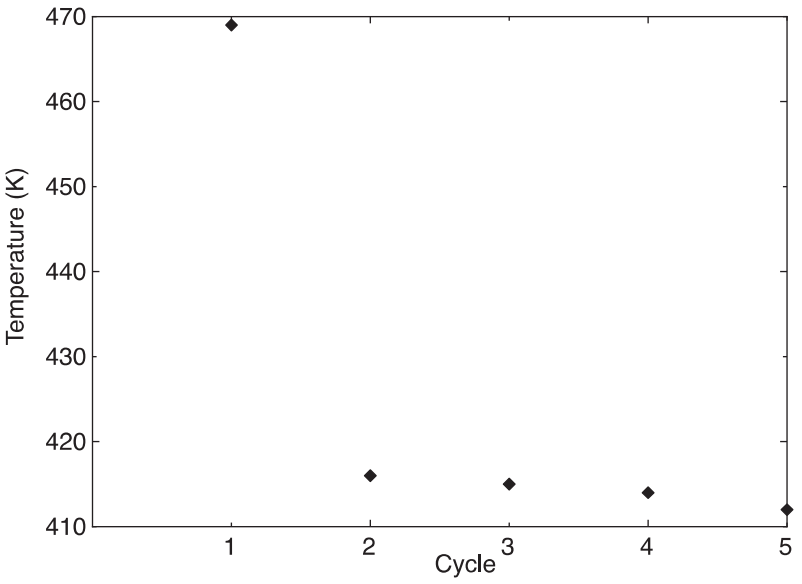

Fig. 8. Peak desorption temperature of $\mathrm{CO}$ at the end of each cycle of EUV and $\mathrm{H}_{2}$ exposure to a $\mathrm{CO}_{2}$ dosed $\mathrm{Ru}(0001)$ surface.

TPD measurements (Fig. 8) further show that the peak desorption temperature of the unreacted $\mathrm{CO}$, remaining after the EUV exposure, is $469 \mathrm{~K}$ for the first iteration. This measurement corresponds to the peak desorption temperature from other experiments done at the same and lower partial pressures of hydrogen $\left(10^{-7} \mathrm{mbar}\right)$, corresponding to $\mathrm{CO}$ desorption from a mostly clean surface. For subsequent cycles of EUV $+\mathrm{H}_{2}$ exposure, we see that the peak desorption temperature of $\mathrm{CO}$ drops to $418 \mathrm{~K}$, and remains unchanged thereafter. This indicates that the bonding of $\mathrm{CO}$ to the surface weakens due to the formation of amorphous carbon on the surface.

\section{Conclusions}

This study shows the formation of $\mathrm{H}_{2} \mathrm{O}$ and amorphous carbon when a $\mathrm{CO}_{2}$ dosed $\mathrm{Ru}(0001)$ surface is exposed to EUV with a partial $\mathrm{H}_{2}$ pressure of at least $1 \times 10^{-5} \mathrm{mbar}$. We have shown that the reaction pathway proceeds via the partial dissociation of $\mathrm{CO}_{2}$ into $\mathrm{CO}$ and $\mathrm{O}$. This dissociation is not driven by photo-induced processes, but is due to catalytic activity at the Ru surface. The overall photo-induced reaction of $\mathrm{CO}_{2}$ and $\mathrm{H}_{2}$ forms water and an amorphous carbon layer, which may be partially hydrogenated. For the reaction conditions and initial $\mathrm{CO}_{2}$ coverages investigated in this study, the catalytic conversion of $\mathrm{CO}_{2}$ to $\mathrm{CO}$ is rapid compared to photo-induced processes, therefore there is practically no intact $\mathrm{CO}_{2}$ left at the start of the EUV exposure. The possibility of direct EUV-induced $\mathrm{CO}_{2}$ dissociation therefore could not be investigated. When exposing a $\mathrm{CO}_{2}$ dosed surface to EUV photons without $\mathrm{H}_{2}$ present in the background, only catalytic partial dissociation of $\mathrm{CO}_{2}$ into $\mathrm{CO}$ and $\mathrm{O}$ was observed. Photo-dissociation of the formed CO was only observed for simultaneous presence of EUV and $\mathrm{H}_{2}$. For hydrogen pressures below $1 \times 10^{-5} \mathrm{mbar}$, no photo-induced formation of water was observed, even though $\mathrm{CO}$ was dissociated. Only at $1 \times 10^{-5} \mathrm{mbar}_{2}$, formation of water from EUV-induced reactions of hydrogen and oxygen were observed. This indicates that the EUV-induced generation of hydrogen radical species is most likely the rate-limiting step for the overall reaction. Cycles of $\mathrm{CO}_{2}$ dosing without cleaning show that the carbon layer covers the Ru surface, reducing the partial dissociation of $\mathrm{CO}_{2}$ and slowing the production of water in later cycles. This confirms that EUV-induced $\mathrm{CO}_{2}$ dissociation is either negligible, or does not lead to any detectable reaction products.

These results can be understood in view of previously reported research on EUV-induced and thermal reactions of hydrocarbons, $\mathrm{CO}_{2}$ and hydrogen on Ru surfaces. Experimental and theoretical results on $\mathrm{CH}_{4}$ adsorption on $\mathrm{Ru}(0001)$ showed that dissociative $\mathrm{CH}_{4}$ adsorption results in $\mathrm{CH}_{2}$ groups and surface hydrogen, which further dissociate to $\mathrm{CH}+\mathrm{H}$ after annealing to $273 \mathrm{~K}$ [27]. Theoretical results in that work show that hydrogenation of carbon species would require significantly higher pressures (in the bar range) than used in this study, which explains our finding that no hydrocarbons or alcohols are found as reaction products. Instead dissociation and surface carbon formation dominates. Similarly, reported theoretical [28] and experimental [29] results on hydrogenation of $\mathrm{CO}_{2}$ by $\mathrm{H}_{2}$ on Ru refer to hydrogen pressures in the range of 1 bar. EUV irradiation in hydrogen background leads to formation of hydrogen radicals, which are able to clean surface oxygen by $\mathrm{H}_{2} \mathrm{O}$ formation [30] and surface carbon by formation of volatile $\mathrm{CH}_{\mathrm{x}}$ species $[15,31,32]$. The results of this work show that $\mathrm{H}_{2} \mathrm{O}$ formation from surface $\mathrm{O}$ is already effective at a hydrogen pressure of $1 \times 10^{-5} \mathrm{mbar}$ and a sample temperature below $90 \mathrm{~K}$, while for removal of surface $\mathrm{C}$ requires higher hydrogen pressure and/or sample temperatures, in line with the results mentioned in Chen et al. [33]. 


\section{Acknowledgements}

This research is supported by the Dutch Technology Foundation STW (project number 140930), which is part of the Netherlands Organization for Scientific Research (NWO), and partly funded by the Ministry of Economic Affairs as well as ASML and ZEISS. We also acknowledge the financial and facilitary contributions by ASML, ZEISS, Malvern Panalytical, and the Province of Overijssel through the Industrial Focus Group XUV Optics at the MESA + Institute, University of Twente. The authors would like to thank Ms. Małgorzata Pachecka, Mr. Luc Stevens, Mr. John de Kuster and Mr. Goran Milinkovic for technical support.

\section{References}

[1] J.B. Benziger, R.J. Madix, The decomposition of formic acid on Ni(100), Surf. Sci. 79 (2) (1979) 394-412.

[2] J. McCarty, J. Falconer, R.J. Madix, Decomposition of formic acid on Ni(110), J. Catal. 30 (2) (1973) 235-249.

[3] H.-T. Chen, D.G. Musaev, M.C. Lin, Adsorption and dissociation of $\mathrm{CO}_{\mathrm{x}}(\mathrm{X}=1,2)$ on W(111) surface : a computational study, J. Phys. Chem. C 112 (9) (2008) 3341-3348.

[4] M. Asscher, C.T. Kao, G.A. Somorjai, High-resolution electron energy loss spectroscopic study of carbon dioxide adsorbed on rhenium(0001), J. Phys. Chem. 92 (10) (1988) 2711-2714.

[5] A.F. Carley, D.E. Gallagher, M.W. Roberts, Activation of carbon dioxide at low temperatures at aluminium surfaces, Surf. Sci. 183 (1) (1987) L263-L268.

[6] F. Solymosi, The bonding, structure and reactions of $\mathrm{CO}_{2}$ adsorbed on clean and promoted metal surfaces, J. Mol. Catal. 65 (3) (1991) 337-358.

[7] K.P. Kuhl, T. Hatsukade, E.R. Cave, D.N. Abram, J. Kibsgaard, T.F. Jaramillo, Electrocatalytic conversion of carbon dioxide to methane and methanol on transition metal surfaces, J. Am. Chem. Soc. 136 (40) (2014) 14107-14113.

[8] J.C. Bricker, C.C. Nagel, S.G. Shore, Reactivities of ruthenium cluster anions: implications for catalysis of the water-gas shift reaction, J. Am. Chem. Soc. 104 (5) (1982) 1444-1445.

[9] J.M. Sturm, C.J. Lee, F. Bijkerk, Reactions of ethanol on Ru(0001), Surf. Sci. 612 (2013) 42-47.

[10] T. Utaka, T. Okanishi, T. Takeguchi, R. Kikuchi, K. Eguchi, Water gas shift reaction of reformed fuel over supported Ru catalysts, Appl. Catal. A 245 (2) (2003) 343-351.

[11] N. Liu, L. Guo, Z. Cao, W. Li, X. Zheng, Y. Shi, J. Guo, Y. Xi, Mechanisms of the water-gas shift reaction catalyzed by ruthenium carbonyl complexes, J. Phys. Chem. A 120 (15) (2016) 2408-2419.

[12] P. Zhao, Y. He, S. Liu, D.-B. Cao, X. Wen, H. Xiang, Y.-W. Li, H. Jiao, Adsorption and dissociation of $\mathrm{H}_{2} \mathrm{O}$ and $\mathrm{CO}_{2}$ on the clean and o-pre-covered $\mathrm{Ru}(0001)$ surface, Appl. Catal. A 540 (2017) 31-36.

[13] S.-T. Zhang, H. Yan, M. Wei, D.G. Evans, X. Duan, Hydrogenation mechanism of carbon dioxide and carbon monoxide on Ru(0001) Surface: a density functional theory study, RSC Adv. 4 (57) (2014) 30241-30249.

[14] M. Pachecka, J.M. Sturm, C.J. Lee, F. Bijkerk, Adsorption and dissociation of $\mathrm{CO}_{2}$ on Ru(0001), J. Phys. Chem. C 121 (12) (2017) 6729-6735.

[15] T.E. Madey, N.S. Faradzhev, B.V. Yakshinskiy, N.V. Edwards, Surface phenomena related to mirror degradation in extreme ultraviolet (EUV) lithography, Appl. Surf.
Sci. 253 (4) (2006) 1691-1708.

[16] F. Liu, J.M. Sturm, C.J. Lee, F. Bijkerk, Coexistence of ice clusters and liquid-like water clusters on the Ru(0001) surface, Phys. Chem. Chem. Phys. PCCP 19 (12) (2017) 8288-8299.

[17] F. Liu, J.M. Sturm, C.J. Lee, F. Bijkerk, Extreme UV induced dissociation of amorphous solid water and crystalline water bilayers on Ru(0001), Surf. Sci. 646 (2016) 101-107.

[18] W.A. Soer, M.J.J. Jak, A.M. Yakunin, M.M.J.W. van Herpen, V.Y. Banine, Grid spectral purity filters for suppression of infrared radiation in laser-produced plasma EUV sources, in: F.M. Schellenberg, B.M. La Fontaine (Eds.), SPIE, vol. 7271, 2009, pp. 72712Y-72712Y-9.

[19] B.L. Henke, E.M. Gullikson, J.C. Davis, X-ray interactions: photoabsorption, scattering, transmission, and reflection at $\mathrm{E}=50-30,000 \mathrm{eV}, \mathrm{Z}=1-92$, At. Data Nucl. Data Tab. 54 (2) (1993) 181-342.

[20] D.I. Astakhov, W.J. Goedheer, C.J. Lee, V.V. Ivanov, V.M. Krivtsun, K.N. Koshelev, D.V. Lopaev, R.M. van der Horst, J. Beckers, E.A. Osorio, et al, Exploring the electron density in plasma induced by EUV radiation: II. Numerical studies in argon and hydrogen, J. Phys. D: Appl. Phys. 49 (29) (2016) 295204.

[21] E.R. Kieft, J.J.A.M. van der Mullen, G.M.W. Kroesen, V. Banine, Time-resolved pinhole camera imaging and extreme ultraviolet spectrometry on a hollow cathode discharge in xenon, Phys. Rev. E 68 (5) (2003) 056403.

[22] B.K. Mund, J.M. Sturm, C.J. Lee, F. Bijkerk, Aromatic structure degradation of single layer graphene on an amorphous silicon substrate in the presence of water, hydrogen and extreme ultraviolet light, Appl. Surf. Sci. 427 (2018) 1033-1040.

[23] P.A. Gerakines, Infrared band strengths: laboratory techniques and applications to astronomical observations, Bull. Am. Astron. Soc. 34 (2002) 911.

[24] A.L. Smith, The Coblentz Society desk book of infrared spectra, in: C.D. Carver (Ed. ), second ed. The Coblentz Society, 1982, pp. 1-24.

[25] H. Pfnür, D. Menzel, F.M. Hoffmann, A. Ortega, A.M. Bradshaw, High resolution vibrational spectroscopy of $\mathrm{CO}$ on $\mathrm{Ru}(001)$ : the importance of lateral interactions, Surf. Sci. 93 (2) (1980) 431-452.

[26] P.A. Taylor, P.B. Rasmussen, C.V. Ovesen, P. Stoltze, I. Chorkendorff, Formate synthesis on $\mathrm{Cu}(100)$, Surf. Sci. 261 (1) (1992) 191-206.

[27] H. Kirsch, X. Zhao, Z. Ren, S.V. Levchenko, M. Wolf, R.K. Campen, Controlling $\mathrm{CH}_{2}$ dissociation on $\mathrm{Ru}(0001)$ through surface site blocking by adsorbed hydrogen, J. Catal. 320 (Suppl. C) (2014) 89-96.

[28] T. Avanesian, G.S. Gusmão, P. Christopher, Mechanism of $\mathrm{CO}_{2}$ reduction by $\mathrm{H}_{2}$ on

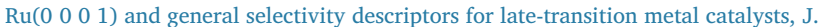
Catal. 343 IS- (2016) 86-96.

[29] M.R. Prairie, A. Renken, J.G. Highfield, K. Ravindranathan Thampi, M. Grätzel, A Fourier transform infrared spectroscopic study of C02 methanation on supported ruthenium, J. Catal. 129 (1) (1991) 130-144.

[30] I. Nishiyama, H. Oizumi, K. Motai, A. Izumi, T. Ueno, H. Akiyama, A. Namiki, Reduction of oxide layer on Ru surface by atomic-hydrogen treatment, J. Vac. Sci Technol. B 23 (6) (2005) 3129-3131.

[31] J. Chen, E. Louis, C.J. Lee, H. Wormeester, R. Kunze, H. Schmidt, D. Schneider, R. Moors, W. van Schaik, M. Lubomska, et al., Detection and characterization of carbon contamination on EUV multilayer mirrors, Opt. Express 17 (19) (2009) 16969-16979.

[32] J. Chen, E. Louis, H. Wormeester, R. Harmsen, R. van de Kruijs, C.J. Lee, W. van Schaik, F. Bijkerk, Carbon-induced extreme ultraviolet reflectance loss characterized using visible-light ellipsometry, Meas. Sci. Technol. 22 (10) (2011) 105705.

[33] J. Chen, E. Louis, R. Harmsen, T. Tsarfati, H. Wormeester, M. van Kampen, W. van Schaik, R. van de Kruijs, F. Bijkerk, In situ ellipsometry study of atomic hydrogen etching of extreme ultraviolet induced carbon layers, Appl. Surf. Sci. 258 (1) (2011) $7-12$. 